\title{
Preface: Social issues in transport planning
}

\author{
Rafael H. M. Pereira ${ }^{*} \quad$ Geneviève Boisjoly ${ }^{* *}$
}

The field of transport planning has been historically dominated by a technical perspective. In its origins, the planning of modern cities and regions was largely developed by engineers with a technocratic understanding of how transportation systems should work, primarily geared towards efficiency (Banister, 2002, Hanson \& Giuliano, 2004). Over the last decades, the field gradually became more interdisciplinary with growing contributions from scholars and professionals from various backgrounds such as geography, urban planning, economics and sociology (Uteng, \& Cresswell, 2008, Hickman et al, 2015, Vickerman, 2021). Transport planning became more diverse. This gave visibility to a variety of social issues that pervade human mobility systems as well as to the political processes that exist alongside the technical aspects of planning.

Concerns about social issues are not new in transport studies. In the late 1960s, a growing number of researchers started to investigate transport inequalities related to access to job opportunities and car dependence (Kain, 1968; Wachs \& Kumagai, 1973, Rosenbloom and Altshuler, 1977) and the distribution of transport subsidies (Abe, 1975; Hefner, 1972, Hanson, 1992). Earlier studies have also examined issues of fairness in transport decision-making processes (Grant, 1975, Booth \& Richardson, 2001) and social and racial inequalities in exposure to environmental externalities (Appleyard \& Lintell, 1972, Forkenbrock \& Schweitzer, 1999). Several studies and reports were published as post-war urban structure changes driven by a car-oriented planning exacerbated issues of race, poverty and unemployment (Kain \& Meyer, 1970; Pignatar \& Falcocch, 1969, O'Regan \& Quigley, 1998; Sanchez, 2008). The early literature on social issues in transportation were very much concerned with transport poverty, giving particular attention to the growing importance of public transport systems in catering for the needs of transit-dependent populations, usually low-income and minority households. Since the late 1960s, we have seen a growing number of more diverse and intricate social issues emerge from how our cities and transport systems are organized.

The aim of this book is to present an up-to-date and critical review of some of the most pressing and sometimes overlooked social issues identified by scholars and practitioners working on transport

\footnotetext{
* Institute for Applied Economic Research - Ipea, Brazil. Corresponding author: rafael.pereira [at] ipea.gov.br

** Polytechnique Montréal
} 
Pereira, R. H. M. \& Boisjoly, G. (2021). Preface: Social issues in transport planning. In R. H. M. Pereira \& G. Boisjoly (Orgs.), Social Issues in Transport Planning (Advances in Transport Policy and Planning Vol. 8, p. xi-xxiii). Elsevier. https://doi.org/10.1016/S2543-0009(21)00052-4

planning. The book gathers a collection of chapters that cover a diverse range of topics such as transport poverty and car dependence, transit-induced gentrification, accessibility, gender, race, children's mobility, the governance of paratransit, equity in project appraisal as well as customer satisfaction with public transport and the potential of research methodologies in promoting more inclusive and participatory transport planning. The book also presents a rich interdisciplinary perspective on these issues based on the expertise of authors from diverse backgrounds and speaking from different contexts, including Latin America, Africa, South Asia, Europe and North America.

Which social issues are considered worthy of public attention in the transport planning process depends on local and historical context. In particular, it depends on the conceptions of a just city and mobility system embedded in the social norms and institutions of each society. This is because every social issue only becomes recognized as a social problem that requires policy attention inasmuch as its manifestation goes against our aspirations of justice and against our understanding of how ethics should be applied to transport planning (van Wee, 2011). While the idea of justice is constantly evolving, there is growing consensus that a full understanding of justice in modern societies involves moral concerns with both equity, democracy and diversity (Kymlicka, 2002, Fainstein, 2010, Davoudi \& Brooks, 2014). Ultimately, every social issue faced by transport planners and scholars is related to how these three pillars of justice can be understood in the field of transport planning (Pereira and Karner, 2021).

The concern with equity is centered around distributive justice (Pereira et al, 2017). It relates to how social and economic inequalities are shaped by the institutions and rules that govern society. Questions of equity draw attention to the distributional outcomes of policies. Equity concerns provoke us to question what social groups benefit or lose from transportation policies, for example in terms of accessibility gains or in terms of health damage due to exposure to pollution. Government policies have a crucial role to play in social democracies through the provision of public goods and services. This is particularly true in the provision of mass transportation infrastructure and services, which often involves the mobilization of substantial resources and construction of large infrastructure projects which cannot be easily provided in a decentralized manner through local communities. In this sense, public transport services and investments will remain one of the key drivers that can shape spatial inequalities of development and opportunities in cities (Tonkiss, 2013), making the study of equity in transport policies particularly important.

Meanwhile, the concern with democracy focuses on the fairness of governance, political participation, and decision making-processes. It is based on the core principle that everyone's voice should be equally heard, with particular attention to the need to engage with communities to develop the public 
Pereira, R. H. M. \& Boisjoly, G. (2021). Preface: Social issues in transport planning. In R. H. M. Pereira \& G. Boisjoly (Orgs.), Social Issues in Transport Planning (Advances in Transport Policy and Planning Vol. 8, p. xi-xxiii). Elsevier. https://doi.org/10.1016/S2543-0009(21)00052-4

policies that shape the built environment and transport systems around them (Bickerstaff et al 2002; Davoudi \& Brooks, 2014). In this sense, the democracy pillar of justice challenges us to move beyond periodic voting and to overcome technocratic top-down planning practices by engaging communities in the co-production of urban space and governmental policies.

Finally, the concern with diversity involves the recognition of group-based differences, rights, needs, values and identities as well as promoting diversity in decision-making processes (Young, 1990, Verlinghieri \& Schwanen, 2020). It requires us to acknowledge that participatory democracy is constantly marked by structural imbalances of wealth and power that marginalize certain groups and favor others in their ability to influence policy decisions that produce urban space (Enright, 2019). The pillar of diversity reminds us that justice is also fundamentally about the uplifting of minorities and marginalized communities, and that justice involves a constant political dispute over which rights, needs and entitlements should be recognized and for whom.

This book speaks directly to this broad understanding of transport justice and how it applies to a variety of social issues present in transport planning. The reader of this book will notice that each chapter addresses a pressing social issue in transport and which touches on one or more of the three pillars of transport justice mentioned above. The first chapters shed light on the diversity of needs and experiences around individuals' mobility and discuss how specific groups are considered in - often marginalized from - current transport planning practices and frameworks.

In chapter 1 "The Roots of Racialized Travel Behavior", Jesus M. Barajas presents an in-depth review of the transport inequities that place Black, Indigenous and people of color at disadvantage in terms of mobility and access to opportunities, with a focus on the United States. The author clearly shows that these patterns partly result from historical and contemporary racism at play at the systemic and individual levels. To start with, racial inequities are strongly rooted in transport planning and urban development policies, which have brought about major distributional inequities in the benefits and burdens of transportation systems (Bullard 2004; Sanchez et al 2007; Rothstein 2017). But the transport inequities go well beyond the configuration of the land use and transport systems. Barajas puts forward several examples to illustrate other (often less tangible) ways in which racism limits individuals in their everyday mobility. These include disproportionate policing arising from racial bias, issues of safety and security in communities of color as well as suspicion arising from individuals perceived as being "out of place" in a neighborhood. This chapter highlights why race-neutral planning processes often exacerbate racial disparities, but it also draws attention to the shortcomings of planning practices and theories that solely 
Pereira, R. H. M. \& Boisjoly, G. (2021). Preface: Social issues in transport planning. In R. H. M. Pereira \& G. Boisjoly (Orgs.), Social Issues in Transport Planning (Advances in Transport Policy and Planning Vol. 8, p. xi-xxiii). Elsevier. https://doi.org/10.1016/S2543-0009(21)00052-4

focus on distributional effects. It then concludes on the need and challenges to appropriately account for race, namely by considering the broader context and domains that affect travel behavior and policies, and calling for a recognition of history and experiences.

An issue that has been historically overlooked by urban and transport planners is how to make planning sensitive to the needs of women, despite women constituting roughly fifty percent of urban populations (Akyelken, 2020; Hanson, 2010; Uteng \& Cresswell, 2008). Tanu Priya Uteng writes the second chapter of this book, presenting an extensive review of the "Gender gaps in urban mobility and transport planning". Drawing from empirical materials of research and practice from both the Global North and Global South, Uteng critically reviews the findings around gendered mobilities and reflects on some of the challenges to mainstream gender in transport and urban planning. The chapter starts by summarizing a range of evidence on the gendered differences in travel behavior. Compared to men, women tend to have more complex travel patterns across space and time of the day. Women also tend to do shorter trips, more trip chaining and are more likely to use active and public transport modes and to be accompanied by small children. As noted by Uteng, these differences emerge due to the interlinks between several factors. These include how women generally have lower access to private transport resources such as cars, the ways in which trip patterns are shaped by women's more complex and intricate scheduling of activities related to non-work activities such as care work, and how women's perceptions of safety have stronger influence on their travel choices or lack thereof. The chapter draws attention to the profound equity implications of how womens' mobility and access to opportunities are often limited due to economic, geographic, time-based, and fear-based exclusion. Finally, the work of Uteng highlights how the predominant male bias in transport planning and even in travel data collection methods and analysis is deeply rooted in a lack of diversity, with little participation of women in the transport sector as employees, as decision-makers in key policy positions and as educators.

Another social group that receives relatively little attention from transport researchers and planners are children (Mitra, 2013; Waygood et al 2019). This is the topic covered in chapter 3 "The Social Dimensions of Children's Travel”, written by E.O.D. Waygood, Pauline van den Berg and Astrid Kemperman. The authors review an extensive literature on children's travel behavior and how it relates to social interactions and connections within a neighborhood, wellbeing and life satisfaction. Since transport planning largely concentrates on the needs of adults (and namely car travel), a declining proportion of children are able to travel independently in several cities of the world. Yet, the authors gather a variety of 
Pereira, R. H. M. \& Boisjoly, G. (2021). Preface: Social issues in transport planning. In R. H. M. Pereira \& G. Boisjoly (Orgs.), Social Issues in Transport Planning (Advances in Transport Policy and Planning Vol. 8, p. xi-xxiii). Elsevier. https://doi.org/10.1016/S2543-0009(21)00052-4

evidence that independent travel by children is associated with multiple positive physical and mental health outcomes. By supporting social interactions and greater social capital, independent travel contributes to greater trip satisfaction and overall social wellbeing. This chapter thereby recommends the design of childfriendly neighborhoods (that facilitate independent travel by children), by promoting active transport and including children in the planning process. Further, the authors highlight the broader social impacts that transport can have on one's life and make a call for researchers and planners to recognize the particular needs of children in urban and transport planning to promote more inclusive cities for all.

The second series of chapters in this book discusses the complex and multi-dimensional interrelationships that contribute to transport inequities. These chapters review how land use and transport development processes, together with institutional and governance structures, foster transport inequities, placing socially disadvantaged groups at risk of transport poverty and social exclusion.

A central concern from transport researchers and planners are the multiple and overlapping dimensions of transport poverty, particularly in the context of car-dependent neighborhoods and cities (Lucas et al, 2016; Mattioli et al 2016). This is the topic covered in chapter 4 "Transport poverty and car dependence: a European perspective”, where Giulio Mattioli makes important links between these issues and questions of transportation equity and justice. Mattioli reviews the conceptual debates around transport equity by discussing the notion of transport poverty from a broad and holistic perspective. As such, the chapter highlights that transport poverty is a multi-dimensional concept that encompasses inequities and distributional issues, both in terms of burdens and benefits. By covering the multiple overlapping dimensions of transport poverty (mobility poverty, transport affordability, accessibility poverty and exposure to externalities), the chapter demonstrates the wide reach of transport poverty across population groups, particularly in Europe and North America. Further, Mattioli emphasizes that transport poverty cannot be understood separately from the societal processes that led to the context of car dependence. As such, in the Global North, and increasingly in the Global South, car access and car use has become a prerequisite for many households to access services and opportunities and to fully participate in the society. This results in several challenges for transport disadvantaged communities in terms of mobility, transport affordability and accessibility, but also in terms of transport externalities associated with car-dominant transport systems.

Transport inequities in rapidly growing cities of the Global South are a pressing concern for transport researchers and planners. In Chapter 5 "Making the links between accessibility, social and spatial 
Pereira, R. H. M. \& Boisjoly, G. (2021). Preface: Social issues in transport planning. In R. H. M. Pereira \& G. Boisjoly (Orgs.), Social Issues in Transport Planning (Advances in Transport Policy and Planning Vol. 8, p. xi-xxiii). Elsevier. https://doi.org/10.1016/S2543-0009(21)00052-4

inequality, and social exclusion: a framework for cities in Latin America”, Daniel Oviedo reviews empirical research on transport provision and poverty and spatial inequalities in access in Latin America, revealing how transport and urban planning contributed to the social exclusion of the poor in the urban peripheries. Drawing on the splintering urbanism and social exclusion frameworks, Oviedo provides a conceptual frame to understand the drivers behind - and impacts of - the lack of accessibility experienced by socially disadvantaged groups. Splintering urbanism, which refers to the differentiated provision of infrastructure based on power, wealth and influence, is helpful in understanding how power and wealth have influenced, and still influence, the development of infrastructure in Latin America. The frameworks used by Oviedo in the chapter helps us understand the paths through which Latin American urbanization has led to well-connected spaces for the elite while leaving areas and communities without political power at the margins of the development processes. Such fragmented development results in a reinforcing cycle of transport disadvantage and inequities, where socially disadvantaged groups are progressively excluded from networks and connected spaces. The proposed framework also illustrates how informal transport, housing and employment strategies work against the structural processes of exclusion. By reviewing transport, development and urban studies, this chapter demonstrates the necessity to consider the multiple dimensions of social exclusion.

As discussed in the previous chapters, the provision of public transport is key to supporting social equity and inclusion by improving accessibility to opportunities. However, the implementation of new transport infrastructure can also lead to gentrification and have negative impacts by pushing out low-income residents and local businesses, harming the populations that would benefit the most from these new infrastructure (Delmelle \& Nilsson, 2020; Padeiro et al 2019; Nilsson \& Delmelle, 2020). This topic is thoroughly reviewed by Elizabeth Delmelle in chapter 6 "Transit-Induced Gentrification and Displacement: The State of the Debate”. The chapter reviews the theoretical foundations and empirical evidence associated with neighborhood changes brought about by investments in rail transit. Delmelle questions the idea that transit alone is responsible for this phenomenon. As such, she exposes mixed findings that have been put forward in previous studies, emphasizing that gentrification-like changes are often marginal and very difficult to quantify. More importantly, Delmelle highlights the importance of the local context in determining how new transport investments will influence the changes in a neighborhood, as well as the need for more disaggregated research to effectively capture the causal effects of transport investments. Again, the complex interrelationships between transport infrastructure, neighborhood change, 
Pereira, R. H. M. \& Boisjoly, G. (2021). Preface: Social issues in transport planning. In R. H. M. Pereira \& G. Boisjoly (Orgs.), Social Issues in Transport Planning (Advances in Transport Policy and Planning Vol. 8, p. xi-xxiii). Elsevier. https://doi.org/10.1016/S2543-0009(21)00052-4

travel behavior and wellbeing are highlighted as key questions to address the equity concerns over who are the winners and losers from transport investments.

The complex interplays between transport systems, urban development and political institutions are further discussed by Jacqueline Klopp in chapter 7 "From 'Para-Transit' to Transit? A Review of the Politics of Popular Transport". The chapter sheds a critical light on the current debates around what is commonly referred to as paratransit of informal transport (e.g. privately or cooperatively owned minibus and taxi systems). The author illustrates that while these forms of transport are typically marginalized and depicted as "chaotic" and "unplanned" by researchers and planners, more and more efforts are placed into integrating these forms of transport in transport planning (Behrens et al, 2016; Cervero \& Golub, 2007; Klopp \& Cavoli, 2019). Klopp thereby refers to them as popular transport rather than paratransit or informal transport, which tends to hold a negative connotation. While the literature reviewed in this chapter increasingly recognizes the potential role of popular transit as first- last-mile options, the question remains on how to effectively work with these modes and engage with their users and stakeholders. If, on the one hand, popular transport has a key role to play in promoting more inclusive cities and transport systems by catering to the needs of low- and middle-income classes, it also poses numerous governance challenges. Some of these challenges discussed in the chapter include the lack of data, labor exploitation, and a profound misunderstanding of operations and issues at stake, but also more broadly the politics around them as well as common attitudes among policy makers. Having demonstrated the complexity of the challenges around the politics and power relations underlying popular transport the author calls for a holistic approach to the governance and planning of these modes in order to promote more equitable and just mobility systems.

The previous chapters emphasized the limitations of current practices in addressing inequities in transport planning. The last chapters provide insights on emerging methods that can contribute to foster more inclusive land use and transport systems.

Customer satisfaction surveys are commonly conducted by transport agencies as a means to identify the diverse needs and experiences of specific population groups (Eboli \& Mazzulla, 2010; van Lierop, Badami \& El-Geneidy, 2018). Yet, there is little systematic understanding on how this type of data is collected and analyzed to help improve overall passengers satisfaction and long-term loyalty. This is the literature gap covered by Cherise Roberts, Emily Grisé and Dea van Lierop in chapter 8 "What are we doing with all that satisfaction data? Evaluating Public Transport customer satisfaction data collection and 
Pereira, R. H. M. \& Boisjoly, G. (2021). Preface: Social issues in transport planning. In R. H. M. Pereira \& G. Boisjoly (Orgs.), Social Issues in Transport Planning (Advances in Transport Policy and Planning Vol. 8, p. xi-xxiii). Elsevier. https://doi.org/10.1016/S2543-0009(21)00052-4

analysis techniques". The chapter focuses on public transport satisfaction data and market segmentation, and how it can contribute to or limit the ability of policy makers to address the needs of all segments of the population, and particularly hard-to-reach minorities. The authors draw attention to some of the advantages and drawbacks of various techniques used by public transport agencies to collect satisfaction data, including intercept and phone surveys, online questionnaires, focus groups and interviews. While quantitative approaches allow reaching a greater number of individuals, achieving representativeness remains a challenge. As for qualitative methods, they allow identifying concerns that are not exposed with quantitative methods and are specifically relevant to highlight experiences of specific, often marginalized, groups. Overall, the authors recommend that a mix of techniques be used to ensure that the perceptions of marginalized groups are captured. Further, the authors insist that careful attention must be placed on the data that is collected and how it is analyzed to effectively capture the differences across segments. This chapter complements the other chapters in the book by providing a practical perspective on how agencies' practices can foster or hinder the recognition of marginalized groups in planning.

One of the most common tasks in transport planning involves assessing the potential positive and negative impacts of transport policy options. While cost-benefit analysis (CBA) has been the first go-to method used by academics and practitioners for this task, CBA is quite limited in that it does not account for social and distributional impacts of transport projects (Van Wee, 2012, Hickman \& Dean, 2018; Mouter, 2020, 2021). This is the starting point of Chapter 9, where Ruth Shortall and Niek Mouter write about "Social and distributional impacts in transport project appraisals". In this chapter, Shortall and Mouter discuss some fundamental limitations of CBA to account for social impacts and ethical concerns of transport policies, and review the recent developments that seek to overcome the shortcomings of CBA. As discussed by the authors, CBA has been criticized for ignoring that the formation of preferences is inherently a social process that goes beyond a purely economic rationality of individual agents. The chapter also discusses the equity implications of CBA for being fundamentally guided by utilitarian and consequentialist moral reasoning, and by the individual willingness to pay paradigm that often deviates from public preferences. Recent innovations in welfare economics to overcome some of these CBA limitations are also covered in the chapter. These include Participatory Value Evaluation (PVE) and Deliberative Monetary Valuation (DMV), which bring citizens participation and social interactions to help inform the allocation of scarce public resources. Shortall and Mouter move on to summarize the core elements of Multi-criteria assessment (MCA) and Deliberative appraisal methods, and review several cases in which they have been used in transport policy appraisal. Both methods can improve the valuation of transport impacts and public goods 
Pereira, R. H. M. \& Boisjoly, G. (2021). Preface: Social issues in transport planning. In R. H. M. Pereira \& G. Boisjoly (Orgs.), Social Issues in Transport Planning (Advances in Transport Policy and Planning Vol. 8, p. xi-xxiii). Elsevier. https://doi.org/10.1016/S2543-0009(21)00052-4

by taking into account multiple viewpoints and dimensions of well-being that are difficult to translate into monetary terms, and Deliberative appraisal methods in particular also can foster democratic participation and pluralistic perspectives through reasoned discussions between participants. This chapter helps us understand the potentials and pitfalls of various appraisal methods and it warns us that the capacity of each of these methods to genuinely promote a more equitable and democratic transport planning that fosters diversity depends on how participation processes are organized and facilitated.

Finally, in chapter 10 "Innovative field research methodologies for more inclusive transport planning: review and prospect", Gina Porter and Claire Dungey focus on how innovative field research methodologies can support more inclusive transport planning. The authors contrast the technocratic approaches (typically centered on large-scale quantitative data and methodologies) with the need to understand and address the perceptions and experiences of marginalized populations. To do so, effectively engaging with potential users, especially the ones that are marginalized within current practices, is crucial. At the same time, the authors caution that participatory research needs to be carried out with careful consideration of the landscapes of power, politics and vested interests. The chapter covers a wide range of field research methodologies, including in-person interviews and focus groups, go-along methods, coinvestigation practices (excluding researchers' direct presence on the field), joint research and interventions as well as digital methodologies. The authors provide a wealth of examples where such methodologies have allowed uncovering challenges experienced by specific groups and providing a nuanced understanding, as well as challenges that go beyond the infrastructure and services as such (e.g. what surrounds the trips in terms of sociality, the urban fabric, etc). The material presented in the chapter not only illustrates the importance of these innovative field research methodologies to empower communities as peer researchers. It also shows the potential role of such methodologies to have real impact in policy design to further the recognition of the diversity and needs of local communities in local policy making. The authors acknowledge that these approaches are not straightforward and present their own set of challenges, but clearly demonstrate the potential of these methodologies and the relevance of overcoming these challenges. It is our hope that it will bring more researchers to engage with such methodologies, thereby contributing to the development of more inclusive research and planning practices.

The full set of chapters in this book cover some of the most challenging social issues in transport planning, which speak directly to the three pillars of transport justice summarized in this introduction: equity, democracy and diversity. The chapters highlight the complexity of the social aspects of transport, 
Pereira, R. H. M. \& Boisjoly, G. (2021). Preface: Social issues in transport planning. In R. H. M. Pereira \& G. Boisjoly (Orgs.), Social Issues in Transport Planning (Advances in Transport Policy and Planning Vol. 8, p. xi-xxiii). Elsevier. https://doi.org/10.1016/S2543-0009(21)00052-4

given their multidimensional, multiscalar and often less tangible nature. Social issues are interconnected with broader concerns of governance and political institutions, inequalities, social exclusion and urban development, while at the same time being intimately related to very personal experiences. A common element that spontaneously emerged across the chapters in this book, is the acknowledgement that researchers and practitioners need to take more holistic approaches, together with a diverse set of methodologies, to properly address those pressing social issues in local urban and transport planning. Such multidisciplinary approaches and frameworks are essential to tackle the complex interplay between institutions, culture, individuals, planning agencies, transport networks, land use development etc in order to make transport planning more inclusive and just.

This book is a call for action for researchers, planners and decision-makers to not be afraid to dig into these complex issues and to take upon the associated challenges. Addressing these issues demands that we go beyond mainstream traditional methods and practices. Doing so requires a lot of effort, resources and time to make changes towards more progressive and inclusive planning practices. But it is our hope that this book will inspire researchers and practitioners in engaging with pressing social issues, and that it will motivate the research and planning communities to develop, adapt and apply innovative approaches.

\section{References:}

Akyelken, Nihan (2020) Transport for women: who decides what women need? Transport Reviews, 40:6, 687-688, DOI: 10.1080/01441647.2020.1799162

Banister, D. (2002). Transport Planning (2 edition). Routledge.

Behrens, R., McCormick, D., Mfinanga, D. (2016). Paratransit in African cities: operations, regulation and reform. Routledge.

Bickerstaff, K., Tolley, R., \& Walker, G. (2002). Transport planning and participation: the rhetoric and realities of public involvement. Journal of Transport Geography, 10(1), 61-73.

Booth, C., \& Richardson, T. (2001). Placing the public in integrated transport planning. Transport Policy, 8(2), 141-149. https://doi.org/10.1016/S0967-070X(01)00004-X 
Pereira, R. H. M. \& Boisjoly, G. (2021). Preface: Social issues in transport planning. In R. H. M. Pereira \& G. Boisjoly (Orgs.), Social Issues in Transport Planning (Advances in Transport Policy and Planning Vol. 8, p. xi-xxiii). Elsevier. https://doi.org/10.1016/S2543-0009(21)00052-4

Bullard, Robert D. 2004. “The Anatomy of Transportation Racism.” In Highway Robbery, edited by Robert D. Bullard, Glenn S. Johnson, and Angel O. Torres, 15-32. South End Press.

Cervero, R., Golub, A., (2007). Informal transport: A global perspective. Transp. Policy 14, 445-457. https://doi.org/10.1016/j.tranpol.2007.04.011

Davoudi, S., \& Brooks, E. (2014). When does unequal become unfair? Judging claims of environmental injustice. Environment and Planning A, 46(11), 2686 - 2702. doi:10.1068/a130346p

Eboli, L., \& Mazzulla, G. (2010). How to capture the passengers' point of view on a transit service through rating and choice options. Transport reviews, 30(4), 435-450.

Enright, T. (2019). Transit justice as spatial justice: learning from activists. Mobilities, 14(5), 665-680.

Delmelle, E., \& Nilsson, I. (2020). New rail transit stations and the out-migration of low-income residents. Urban Studies, 57(1), 134-151.

Fainstein, S. S. (2010). The just city. Ithaca: Cornell University Press.

Forkenbrock, D. J., \& Schweitzer, L. A. (1999). Environmental Justice in Transportation Planning. Journal of the American Planning Association, 65(1), 96-112. https://doi.org/10.1080/01944369908976036

Grant, J. A. (1975). Urban transportation and decision making-A comparison of three case studies in Britain. Transportation, 4(2), 123-142.

Hanson, M. E. (1992). Automobile Subsidies and Land Use: Estimates and Policy Responses. Journal of the American Planning Association, 58(1), 60-71. https://doi.org/10.1080/01944369208975535

Hanson, S., \& Giuliano, G. (2004). The geography of urban transportation. Guilford Press.

Hanson, S. (2010) Gender and mobility: new approaches for informing sustainability. Gender, Place \& Culture: A Journal of Feminist Geography, 17(1), 5-23.

Hickman, R., Bonilla, D., Givoni, M., \& Banister, D. (2015). Handbook on transport and development. Edward Elgar. 
Pereira, R. H. M. \& Boisjoly, G. (2021). Preface: Social issues in transport planning. In R. H. M. Pereira \& G. Boisjoly (Orgs.), Social Issues in Transport Planning (Advances in Transport Policy and Planning Vol. 8, p. xi-xxiii). Elsevier. https://doi.org/10.1016/S2543-0009(21)00052-4

Hickman, R., \& Dean, M. (2018). Incomplete cost-incomplete benefit analysis in transport appraisal. Transport reviews, 38(6), 689-709.

Kain, J. F. (1968). Housing segregation, negro employment, and metropolitan decentralization. The quarterly journal of economics, 82(2), 175-197.

Kain J., \& Meyer J. (1970) Transportation and poverty. The Public Interest. 18, 75-87.

Klopp, J.M., Cavoli, C., (2019). Mapping minibuses in Maputo and Nairobi: engaging paratransit in transportation planning in African cities. Transp. Rev. 39, 657-676. https://doi.org/10.1080/01441647.2019.1598513

Kymlicka, W. (2002). Contemporary political philosophy: an introduction (2nd ed.). Oxford: Oxford University Press.

Lucas, K., Mattioli, G., Verlinghieri, E., \& Guzman, A. (2016). Transport poverty and its adverse social consequences, Proceedings of the institution of civil engineers-transport, 169(6), 353-365.

Mattioli, G., Roberts, C., Steinberger, J. K., \& Brown, A. (2020). The political economy of car dependence: A systems of provision approach. Energy Research \& Social Science, 66, 101486.

Mitra, R., 2013. Independent mobility and mode choice for school transportation: A review and framework for future research. Transport reviews 33(1), 21-43.

Mouter, N. (2020). Standard Transport Appraisal Methods (Advances in Transport Policy and Planning Vol. 6). Elsevier.

Mouter, N. (2021). New Methods, Reflections and Application Domains in Transport Appraisal (Advances in Transport Policy and Planning Vol. 7). Elsevier.

Nilsson, I., \& Delmelle, E. C. (2020). Impact of new rail transit stations on neighborhood destination choices and income segregation. Cities, 102, 102737.

O'Regan, K., \& Quigley, J. (1998). Accessibility and economic opportunity. Retrieved from SSRN: http://escholarship.org/uc/item/37h6t700\#page-1 
Pereira, R. H. M. \& Boisjoly, G. (2021). Preface: Social issues in transport planning. In R. H. M. Pereira \& G. Boisjoly (Orgs.), Social Issues in Transport Planning (Advances in Transport Policy and Planning Vol. 8, p. xi-xxiii). Elsevier. https://doi.org/10.1016/S2543-0009(21)00052-4

Padeiro, M., Louro, A., \& da Costa, N. M. (2019). Transit-oriented development and gentrification: A systematic review. Transport Reviews, 39(6), 733-754.

Pignatar L., \& Falcocch J. (1969) Transportation needs of low-income families. Traffic Quarterly. 23(4), 505-525.

Pereira, R. H. M., Schwanen, T., \& Banister, D. (2017). Distributive justice and equity in transportation. Transport Reviews, 37(2), 170-191. doi:10.1080/01441647.2016.1257660

Pereira, R. H. M. \& Karner, A. (2021) Transportation Equity In: Vickerman, Roger (eds.) International Encyclopedia of Transportation vol 1. pp.271 - 277. United Kingdom: Elsevier Ltd

Rosenbloom, S. A. and Altshuler (1977). "Equity Issues in Urban Transportation, Policy Studies Journal 6(1), pp 29-39.

Rothstein, Richard. 2017. The Color of Law: A Forgotten History of How Our Government Segregated America. New York; London: Liveright Publishing Corporation.

Sanchez, T. W. (2008). Poverty, policy, and public transportation. Transportation Research Part A: Policy and Practice, 42(5), 833-841.

Sanchez, Thomas W., and James F. Wolf. 2007. "Environmental Justice and Transportation Equity: A Review of MPOs." In Growing Smarter: Achieving Livable Communities, Environmental Justice, and Regional Equity, edited by Robert D. Bullard, 249-71. Cambridge, MA and London, UK: MIT Press.

Uteng, T. P., \& Cresswell, T. (2008). Gendered mobilities. Ashgate: Aldershot, Routledge.

van Lierop, D., Badami, M., \& El-Geneidy, A. (2018). What influences satisfaction and loyalty in public transport? A review of the literature. Transport Reviews, 38(1), 52-72. https://doi.org/10.1080/01441647.2017.1298683

van Wee, B., 2011. Transport and Ethics: Ethics and the Evaluation of Transport Policies and Projects. Edward Elgar Pub, Cheltenham. 
Pereira, R. H. M. \& Boisjoly, G. (2021). Preface: Social issues in transport planning. In R. H. M. Pereira \& G. Boisjoly (Orgs.), Social Issues in Transport Planning (Advances in Transport Policy and Planning Vol. 8, p. xi-xxiii). Elsevier. https://doi.org/10.1016/S2543-0009(21)00052-4

van Wee, B. (2012). How suitable is CBA for the ex-ante evaluation of transport projects and policies? A discussion from the perspective of ethics. Transport Policy, 19(1), 1-7.

Verlinghieri, E., \& Schwanen, T. (2020). Transport and mobility justice: Evolving discussions. journal of transport geography, 87, 102798.

Vickerman, R. (Org.). (2021). International Encyclopedia of Transportation ( $\left.1^{\circ} \mathrm{ed}\right)$. Elsevier.

Young, I.M., 1990. Justice and the Politics of Difference. Princeton:, Princeton University Press.

Wachs, M., \& Kumagai, K. (1973). Physical accessibility as a social indicator. Socio-Economic Planning Sciences, 7(5), 437-456. https://doi.org/10.1016/0038-0121(73)90041-4

Waygood, E.O.D., Friman, M., Olsson, L., Mitra, R. (2019.), Transport and Children's Wellbeing. Elsevier, pp. 237-252 